
reproduction in any medium, provided the original work is properly cited.

\title{
Emergence of multiplex mobile phone communication networks across rural areas: An Ethiopian experiment
}

\author{
PETR MATOUS \\ School of Engineering, University of Tokyo, 7-3-1 Hongo, Bunkyo-ku, Tokyo 113-8656, Japan \\ (e-mail: petr@civil.t.u-tokyo.ac.jp) \\ YASUYUKI TODO \\ Department of International Studies, Graduate School of Frontier Sciences, University of Tokyo, \\ Kashiwa-no-ha, Chiba, Japan \\ (e-mail: yastodo@k.u-tokyo.ac.jp) \\ T A T S U Y A ISHIK A W A \\ School of Engineering, University of Tokyo, 7-3-1 Hongo, Bunkyo-ku, Tokyo 113-8656, Japan \\ (e-mail: ishikawa@ken-mgt.t.u-tokyo.ac.jp)
}

\begin{abstract}
Mobile phones are spreading to remote areas of the globe, leading to the following question: "What is the potential of the new communication technologies for increasing individuals" access to information and the diffusion of attitudes and practices across rural areas of developing countries?" We have donated phones to 234 farmers selected by stratified random sampling in an agrarian region of Ethiopia and have tracked their main communication partners for six months. The panel data and qualitative interviews indicated that the phones were not typically used to expand the existing constrained social networks or to gain information from new sources but to call contacts who had been known personally and to individuals introduced through the experiment. Stochastic actor-based network models clarified that although agricultural information-seeking and casual calling are intertwined, the mechanisms underlying the evolution of instrumental and expressive communication networks are distinct. Acquaintances living beyond comfortable walking distances and individuals whom others call became preferred for information-seeking calls. Thus, mobile phones may accelerate information exchange within existing social networks and may support the creation of new information hubs that might facilitate more efficient information diffusion over long distances in the future. In contrast, the importance of geographical communities strongly prevails in casual phone conversations. Physically proximate community members who tend to be met frequently were preferred for sentiment-sharing calls. Preferential attachment was not evident for this type of communication. As a result, the network of these expressive calls was highly localized and fragmented, making it unlikely for personal feelings to diffuse across wide geographical areas through the new phone networks.
\end{abstract}

Keywords: multiplex network evolution, stochastic actor-based models, information and communication technology for development

\section{Introduction}

A large proportion of inhabitants of developing countries are employed in agriculture. In Ethiopia, the nationwide average (in which large urban areas are also 
included) is approximately $80 \%$ (Central Statistical Agency, 2004). Ethiopian rural areas are populated by small-scale subsistence farmers who cultivate $95 \%$ of all Ethiopian crop land and account for $90 \%$ of the national production (Deressa, 2007). For university graduates, one of few employment opportunities beyond farming in Ethiopian villages is as an expert agricultural advisor. However, despite the prevalence of agriculture across the society, Ethiopia remains dependent on food aid because of inefficient and ecosystem-degrading farming practices (Bewket, 2007; Deressa, 2007; Mojo et al., 2010). A lack of information has been cited as the main barrier to Ethiopian farmers' adoption of more sustainable and effective practices (Deressa et al., 2009). Since 1970, agricultural experts have reportedly increased their efforts to improve information dissemination within the sector but with little success (Gebremedhin \& Swinton, 2003).

The international development literature is highly optimistic about the role of mobile phones in increasing farmers' access to information (Donner, 2008; Juma, 2010). The social networks of inhabitants of rural areas that lack transportation infrastructure are constrained by the maximum walking distance (Matous et al., 2013). Mobile phones are expected to enable farmers in such areas to expand their networks and reach beyond the locus of their everyday face-to-face interactions to access information about production techniques and markets (Donner, 2008). In the first decade of the 21st century, mobile telephony in Africa has grown faster than in any other region of the world (International Telecommunication Union, 2009).The number of mobile phone subscriptions in Ethiopia has been rising by a compound annual rate of $128 \%$ (International Telecommunication Union, 2009, pp. 14-15), which is the second-highest rate in Africa, after Guinea-Bissau. The transformation of local networks and the compression of time and space are cited as the central aspects of value creation by mobile phones on the continent (Ilahiane \& Sherry, 2012). This relation between mobile phones and social networks is of great interest to academics and practitioners because where mass media are lacking and literacy rates are low, webs of interpersonal communication play a crucial role in information diffusion.

However, it is questionable whether the expectations regarding the spatial expansion of social networks as a result of mobile phone technology are justified. It is known that even in industrialized countries with highly mobile populations, the probability of a communication link between landline phone users (Fischer, 1992; Mok \& Wellman, 2007; Singer, 1981; Wellman \& Tindall, 1993) as well as mobile phone users (Barthélemy, 2011; Krings, Calabrese, Ratti, \& Blondel, 2009; Lambiotte et al., 2008) decreases with distance. Presumably, the sensitivity of phone calls to distance in pedestrian societies where the mobile phone is the only information communication technology might be significantly higher. Can mobile phones be relied on for a wide diffusion of essential information, or are they only used with a limited number of friends from the same neighborhood?

A number of evaluation studies from developing countries have found positive impacts of mobile phones on access to agricultural information (Arunachalam, 2002; Bhavnani et al., 2008; Overå, 2006), whereas other studies have found mobile phones to be used mainly for casual conversations within existing networks rather than as a means to increase productive capacity (Donner, 2006, 2009; Horst \& Miller, 2005; Matous et al., 2011). These findings parallel the situation when the first landline phones were being used in Western countries. Although landline phones 
were originally marketed in remote rural areas as tools for business and means of connecting with urban centers, a widespread diffusion of telecommunication was achieved largely due to the popularity of phones for casual calls (Fischer, 1992).

Although communication for self-expression is important in any country, this type of phone usage is mostly neglected in the literature on information technologies for developing countries (Donner, 2009). This lack of consideration is unfortunate because sentiment-sharing conversations are a crucial source of social support and nurture informal relations (Campbell \& Kelley, 2008), which in turn may become instrumental in times of need (Krackhardt \& Stern, 1988).

Understanding the interaction between face-to-face communication and phone calls as well as the evolution of information- and sentiment-sharing networks across physical space in underdeveloped rural areas can help researchers identify potential paths to productivity enhancement and better understand the social and psychological outcomes of mobile use in developing countries. As long as the geography of the different types of calls remains unexplored, it will be problematic to design effective interventions with new information technologies or understand social diffusion processes in less-developed regions with access to mobile phone telephony.

The research question addressed in this paper is as follows: "What is the potential of the new communication technologies in individuals' access to information and diffusion of practices and sharing of sentiments across rural areas of developing countries?" Specifically, we focus our analysis on two newly emerging types of communication networks: (1) information-sharing and (2) sentiment-sharing mobile phone call networks. The paper identifies how geography and network structure influence individuals' choices of information sources and casual calling partners in a historically pedestrian society. We discuss the topologies of macro-communication network structures that may develop through these micro-tendencies. For this purpose, we created conditions in a non-industrialized Ethiopian region that enabled us to quantitatively and qualitatively observe this new network evolutionary mechanism from its beginning.

\section{Theoretical framework}

\subsection{Instrumental and expressive communicative action}

According to Lin (2001), individuals act for two primary purposes, instrumental and expressive, and any theory linking individuals to structure must distinguish these two classes of actions. We borrow this framework to classify communication activities in the present paper. An explanation of these two types of activities follows.

Instrumental actions are undertaken to achieve certain goals, and the means to achieve them are separate and distinct from the goals themselves. Through instrumental actions, egos seek alters who are in different, preferably better, social positions to gain access to resources that are not directly available to the egos. This behavior requires egos to demonstrate a high degree of agency to overcome normative homophilous interaction patterns (McPherson et al., 2001). Weak ties are often more likely than strong ties to reach new fresh resources that are unavailable to ego (Granovetter, 1973), also partly because weak ties tend to be more numerous than maintenance-demanding strong ties. In the present paper, we focus 
solely on instrumental communication related to agriculture. For Ethiopian farmers, potentially highly valuable sources of instrumental support, information, and new technologies are the university-educated experts who work for the public agricultural extension centers (Matouš et al., 2012). However, the Ethiopian extension system is hierarchical, and the experts' status is significantly above that of the farmers (Matouš et al., 2012). Although the underprivileged egos may have much to gain in such asymmetric relationships, alters with better resources might not be interested in engaging with the egos.

Expressive needs, specifically those seeking sentiment and mental support, are a strong driving force in people's behavior (Lin, 2001). Expressive actions are taken for their own sake; they are both means and ends. Such actions can include soliciting and sharing support or confiding one's feelings, as when mothers talk affectionately to each other about their children or complain about their husbands. The partners for expressive activities are "expected to sympathize and empathize with ego and to appreciate and reciprocate ego's feelings" (Lin, 2001, p. 46). Consequently, individuals with similar socioeconomic characteristics and lifestyles are the preferred partners for expressive actions (Homans, 1950; McPherson et al., 2001). Empathy and common concern are associated with frequent social interactions. Thus, in a context characterized by underdeveloped transportation infrastructure, the extent of expressive activities is expected to be geographically limited (Matous et al., 2013).

Naturally, instrumental and expressive actions are interrelated and may support each other. Instrumental information may be more readily shared after trust has been built through expressive interactions, and business partners may become true friends. This study uses the instrumental and expressive conceptualization of communication networks to achieve the two aims of this paper, i.e., to ascertain the potential of the mobile phone for (1) the diffusion of agricultural information and (2) the potentially interrelated expression of sentiments.

\subsection{Phone-call network normative processes and social learning in agriculture}

Traditionally, governmental agricultural advisors were expected to spread effective practices by teaching them to selected "pilot farmers," who were expected to pass the knowledge on to the passive remainder of the population. However, researchers have recognized the limits of this top-down linear model (Douthwaite et al., 2001; Leeuwis, 2004; Spielman et al., 2009; Warner, 2007). It is assumed now that farmers mutually influence each other in many directions in their agricultural decisions (Solano et al., 2003; Schneider et al., 2009), and social learning is expected to play a large role in the protection of farmers' natural resources (Ostrom, 1990; Folke, 2006; Janssen et al., 2006; Bodin \& Crona, 2009; Pretty et al., 2011).

To investigate the potential contribution of the mobile phone to agricultural social learning, we must examine micro-mechanisms that may lead to the emergence of knowledge-sharing macro-structures within communities. In general, theoretically important drivers of network evolution are actors' tendencies toward initiating a contact, reciprocity, and preferential attachment (Snijders, 2001), and results from industrialized countries show that mobile phone networks are no exception to this pattern (Akoglu \& Dalvi, 2010; Hidalgo \& Rodriguez-Sickert, 2008). More specifically to the Ethiopian context, it is clearly important whether people use their 
phones at all. The tendency to call others in the community or withdraw from using the phone is a crucial determinant of the density of the network. Then, for a given network density, the network topology determines the potential for information diffusion among the actors. Well-connected, high-degree nodes can emerge due to preferential attachment, i.e., an actor's tendency to create ties to popular actors (Barabási, 2009; Barabási \& Albert, 1999). It is also of interest to determine whether bidirectional information and feedback exchange can occur (i.e., whether pairs and triplets of farmers can consider each other as important information sources) or only unidirectional flows of information from more informed individuals to other passive recipients can be expected. Preferential attachment in combination with the possibility of reciprocating attention would support the creation of star-like huband-spoke structures with interactive relationships and flows of information between the evolved centers and the surrounding nodes. Such centers connect many people within few steps in the network and theoretically enable a wide sharing of knowledge generated through experience, experimentation, and reinvention.

Social status and social capital have been hypothesized to affect such endogenous tendencies in advice networks (Agneessens \& Wittek, 2012; Lazega et al., 2012). From the status perspective, giving advice generates prestige, whereas requesting information decreases it. According to this view, we would expect unidirectional flows of information from knowledgeable individuals who have accumulated higher status in the local hierarchy to lower status individuals. In network terms, this phenomenon would be manifested by an actor's avoidance of reciprocation and cyclical triads (Agneessens \& Wittek, 2012). The social capital perspective predicts that exchange relations create obligations that must be returned (Molm et al., 2007). Moreover, in cases of generalized exchange, an old favor might not necessarily be returned by the original debtor but possibly by an individual who is indebted to the original debtor. In network terms, these effects would be manifested by actors' preferences for reciprocation and cyclical triads (Agneessens \& Wittek, 2012).

These endogenous tendencies are estimated in this study and controlled in the assessment of the net effects of other factors (e.g., geography) on the formation of instrumental and expressive calling networks. The process is described in the Methods section below.

\section{Methods}

This study combines several methods. We donated mobile phones to farmers in rural Ethiopia, where usage rates were low, and collected longitudinal network data on communication ties and their content. Analytically, we took advantage of the most recent advances in stochastic actor-based modeling to explain the mechanisms of the calling network evolution in a statistically rigorous manner. Finally, semi-structured interviews with the experts and selected farmers enabled a meaningful interpretation and validation of the findings regarding people's networking activities.

Donating hundreds of phones may be considered a particularly atypical aspect of this study. The following section explains the relevance of this research design. 


\subsection{Experimental intervention}

Identifying new phone users' micro-behaviors that determine the topology of the overall communication network entails several challenges related to self-selection, network growth, and relevant data accessibility.

The first users of new communication technologies tend to be wealthier individuals with specific personal characteristics and social networks (May, 2012; Peters \& Allouch, 2005; Rogers, 2003). If we attempted to capture the changing dynamics in usage of the first information-communication technologies under natural conditions, the observations would include only advantaged individuals who could only call each other. Alternatively, if we monitored the natural situation at subsequent stages, after later adopters had joined the existing calling network, the process would be influenced by the shape of the pre-existing calling network. Even if all individuals began with the same number of calling ties randomly distributed without preferential attachment, the early adopters would evolve to have the highest degree in the network (Barabási \& Albert, 1999). Another problem is obtaining relevant data from the users, as directly unobservable egos' perceptions of their communication partners are important for information and behavior diffusion (Rogers, 2003). With regard to the adoption of new farming practices, data on who is considered to be an important partner for information gathering and self-expression may be more relevant than simple blind logs of who calls whom. The perceived purpose of communication activities is also of interest. Such data are difficult to obtain under natural conditions.

This paper attempts to understand the behavior of individuals from all levels of the Ethiopian rural farming society at the initial stages of new technology introduction. Exogenously creating conditions in one of the remaining areas where mobile phones had not yet been popular allowed for rigorous statistical judgments about the users' preferences and enabled quantitative descriptions of the emergence of the overall communication network from the beginning. The large-scale randomized donation of mobile phones enabled the inclusion of users representing all socio-economic groups to participate in the network creation from the beginning of the observation. While limiting confounding by self-selection and pre-existing calling history, this intervention illuminated people's changing attitudes toward the new technology and the technology's usage for information gathering and mental well-being. Importantly, in return for the valuable devices, the participants were willing to share details of their usage and regularly answer demanding and potentially intrusive questions regarding their perceived main communication partners and calling purposes. This data acquisition might be impossible if the participants had purchased the phones.

\subsection{Data description}

Despite the rapid growth in mobile phone penetration in Ethiopia, prior to the experiment, the national average was only four subscriptions per 100 inhabitants, the third lowest on the continent (International Telecommunication Union, 2009). In May 2011, we donated mobile phones to 234 heads of farming households selected through stratified random sampling in four villages of the Tiyo District in Arsi Zone. This number corresponds to approximately $12 \%$ of the households in these villages. 
The farmers live on land that is allocated by the government, and local laws prevent them from moving their farms. Our previous survey had shown that these farmers had not been using mobile phones frequently prior to the experiment and that their social networks and economic activity had been geographically constrained. Almost every individual known to these farmers lived within a two-hour walking distance, face-to-face meetings were essentially the only mode of contact, and people who lived beyond one kilometer were met only infrequently (Matous \& Todo, 2013). Thus, we had a rare opportunity to observe the emergence of phone communication networks from the beginning.

Together with the phones, we provided lists with the names and phone numbers of all individuals who were given a phone in the area. We also added the numbers of 27 local agricultural experts who helped to organize the experiment and five Ethiopian research assistants who already owned phones.

The agricultural experts charged each phone with a credit worth approximately 30 minutes of domestic calls to ensure that the farmers used their phones. Every month, up to three research assistants separately interviewed the farmers about their phone usage in exchange for another 30-minute calling credit. This process was repeated monthly until December 2011. During each monthly interview, the research assistants asked the farmers about the main interlocutors they had called within the previous month (up to a maximum of five), their relationship (e.g., "kin" or "met just through the experiment"), and the main content of the calls with each elicited alter. The exact GPS coordinates of farmers' households and experts' workplaces were also recorded. Due to the benefits offered to the farmers (a free mobile phone and free calling credit every month) and efforts of the local research assistants, we obtained this longitudinal multivariate communication network dataset with a minimal amount of missing data (Table 2). The 266 people who were included in the distributed lists, i.e., the farmers who received phones, the local agricultural experts, and the experiment organizers, constitute the nodes of the networks in the current paper. In any study employing full networks, the setting of the network boundary can be questioned. Because of the above-mentioned social isolation of the villages and the previous lack of information-communication technologies, we believe that the boundary for the present study is sensible.

An important characteristic of the network data is their self-reported nature. Admittedly, the objectivity of self-reports and the accuracy of the coding of the communication content can be questioned. However, we believe that this type of data can complement the large body of existing literature on phone networks. Face-to-face data gathering regarding communication partners and the nature of calls is demanding but enables the investigation of somewhat different aspects of communication and network formation than do automatically logged datasets. Who the users remember and report among their top five communication partners is informative, and the nominations can be used to define the direction of ties in the analyzed networks. The tie direction does not necessarily reflect who initiated the calls; however, it reveals who in the pair perceives the other person as an important phone communication partner for agricultural information provision or companionship. For example, if there is an information tie from A to B, we know that $\mathrm{A}$ considers $\mathrm{B}$ to be an important calling partner for information gathering. In contrast, if there is no tie from B to A, B either consciously named individuals other 
than $\mathrm{A}$ or did not recall $\mathrm{A}$ during the interview. In either case, we assume that $\mathrm{A}$ is not an important information source for B. Consequently, we assume that $\mathrm{A}$ is likely to pay more attention and absorb more information from $\mathrm{B}$ than vice versa.

In addition to the monthly surveys, we conducted semi-structured interviews, in February 2012, with the experts $(N=9)$ and selected farmers $(N=8)$ concerning their phone usage. These surveys aided in interpreting the quantitative findings. Working with a skilled interpreter between English and the local languages, Amharic and Oromo, the first author prompted the farmers with a general instruction, such as "Please tell me something about the way you use your phone." The informants could talk freely; when they had said everything that was on their mind, the interviewer followed up with gradually more focused questions. As the conversation unfolded, we inquired about the following sub-topics in a variable order: choice of walking versus calling, perception regarding phone calls with less known persons, methods of obtaining phone numbers, understanding the functions of the phone, use of text messaging, the changing nature of phone usage over time, the value of the phone for instrumental versus expressive purposes, and any other issue that the informant volunteered. The experts had been heavy phone users prior to the experiment. We asked them about the content of the calls they received from the farmers. The experts informed us that they did not usually call farmers and that farmers were not among their top five most important communication partners. In the final stage of this research, we showed them the preliminary results and the anonymized networks, and asked for their opinion on the observed patterns.

\subsection{Multiplexity considerations}

The current paper analyzes the co-evolution of instrumental and expressive communication networks. The importance of exploring complex interplays of multiple relations to understand the patterned nature of social structures was emphasized by early network scholars (Boissevain, 1974; Boorman \& Harrison, 1976; Harrison et al., 1976). However, most network studies and available analytical techniques continue to focus on univariate networks, ignoring the possible dynamic influences of different types of relationships on each other (Rodriguez \& Shinavier, 2010; Szell et al., 2010; Szell \& Thurner, 2010).

This simplification is not always appropriate because analyzing only a single network where multiple networks interact can potentially distort results (Ellwardt et al., 2012; Ferriani et al., 2013; Huitsing et al., 2012; Leicht \& D’Souza, 2009; Szell et al., 2010). The problem is that reliable longitudinal multivariate data are lacking, and appropriate analytical methods that would enable formal theorizing through quantitative testing of hypotheses are under development (Entwisle et al., 2007; Kadushin, 2012). Paradoxically, current phone network studies are driven by the new availability of automatically collected society-wide datasets, which enable researchers to explore social interactions at an unprecedented scale (Onnela et al., 2007). However, this perspective also has drawbacks. It may suffer from coarsegrained representations of social processes, averaging over a multitude of unknown local contexts and millions of unknown diverse users. Furthermore, automatically collected large phone network datasets are blind with respect to the nature of calls (Szell et al., 2010), which is important for our question. 
Analytically, the most common approach to addressing multiplexity is to aggregate all networks into one or to analyze each network separately (either at the wholenetwork level or at the individual level) and then compare the results. However, ignoring potential interdependencies of interest among the networks or mixing different types of relationships may misrepresent the system (Robins \& Pattison, 2006; Szell et al., 2010). Only recently has methodological progress been achieved in research of interdependent networks in terms of community detection, percolation thresholds, and dynamic analysis (Gao et al., 2012; Leicht \& D’Souza, 2009; Mucha et al., 2010; Ripley et al., 2012; Rodriguez \& Shinavier, 2010). These works confirm differences resulting from single and multiplex conceptualizations and inform the present research.

The next section explains our chosen analytical strategy.

\subsection{Analytical strategy}

First, we examine the descriptive statistics of overall and specific calling networks among the 266 actors and visualize them in geographical space for the six monthly observations. This analysis is followed with actor-based modeling. The specifics of these methods are described below.

\subsubsection{Measures}

During the interviews, the research assistants classified the calling ties into agriculturerelated instrumental communication, expressive communication, and other calls. The classification was based on the interviewer's judgment and was confirmed by the interviewee. The interviewers achieved consensus on the meaning of each category among themselves through finalizing the questionnaire, translating it, and testing and retesting it together in the local languages. The informants were asked only about the main conversation topics with each contacted individual for the particular month; the content of separate phone calls was not considered. The instrumental calls include only information-gathering exchanges regarding agricultural practices, technologies, and markets. Expressive calls include casual conversations without specific instrumental goals, mainly sentiment-sharing communication with friends or kin. A tie could be classified as both instrumental and expressive; however, this occurred in only one case. Typically, the users mentioned only agriculture-related topics or only sentiment-sharing topics (or topics unrelated to either of these) as the main topic of conversation for each alter during each monthly interview. Naturally, this does not mean that the farmers spoke strictly only about the main elicited topics. It is unlikely that they would never mention any instrumental issue in a communication link that was described as expressive in a given month. Unfortunately, it was not feasible to conduct a sufficiently deep inquiry to obtain and record all details of all communication in a given month. However, we can see from the available data that some ties changed their nature from mainly instrumental to mainly expressive and vice versa during the experiment.

Based on this classification of ties, unweighted directed instrumental, expressive, and aggregate networks were constructed. In the aggregate calling network, we consider that there is a tie from actor $i$ to actor $j$ if there is any type of tie present. 
The "other" category includes calls about non-farm activities that were unrelated to the exchange of information on agricultural practices, technologies, and markets, and were not of a casual sentiment-sharing nature. The "other" category also includes communication ties that the user was not able or willing to sufficiently describe for classification. Calls of a potentially instrumental nature that were not related to agriculture are also categorized as other. This category is not specifically analyzed in the present paper.

In the case of the overall network, we also test the relation between the calling network structure and call volumes. We use a dichotomized behavioral variable that distinguishes whether the farmer has purchased an extra calling charge to talk beyond the originally provided free monthly charge (approximately 30 minutes per participant).

Independent actor and dyadic covariates used in the presented models are described below.

1. Farmer dummy. Takes a value of 1 if the actor is a farmer and 0 if the actor is a government-employed agricultural expert. Of the actors, $88 \%$ are farmers. No values are missing.

2. Village. A categorical variable indicating the actor's location. Categories 1 to 4 are used for the four farming villages in which we conducted the experiment; 5 indicates urban locations where the experiment organizers and some agricultural experts were based. No values are missing.

3. Physical distance. A dyadic covariate indicating GPS-measured straight geographical distances in kilometers between the actors' households (or the workplaces of the experts). Most of previous studies on the geography of social networks were conducted in societies where individuals can move freely and, thus, can relocate closer to alters with whom they wish to interact. This freedom of movement makes the effects of distance endogenous. However, the effect of distance can be considered exogenous in the present study because Ethiopian laws effectively prohibit farmers from moving and the experts are assigned to their locations on a short-term basis by the government. The nearest pair of actors lived 18 meters apart; the most remote pair (a farmer and an experiment organizer) were 270.4 kilometers apart. The mean value is 7.856 kilometers. In the presented models, this variable is used in a natural logarithmic form, with values ranging from -4.0 to 5.5 . A total of $1,214(1.7 \%)$ values are missing.

\subsubsection{Actor-based model selection and goodness of fit}

Our research problem requires methods that are specifically designed for a longitudinal multivariate network analysis. We take advantage of the latest advances in stochastic actor-based modeling (Ripley et al., 2012; Snijders et al., 2013) to simulate the changes in the two observed networks while accounting for possible interactions, normative network processes, and the effects of geography. The reader is referred to the Appendix and the cited works of Snijders and his colleagues for the technical details of this approach (Snijders, 2001; Snijders et al., 2010; Steglich et al., 2010). This modeling method enables us to uncover farmers' preferences when selecting their calling partners for the sharing of information and sentiments. From 
these micro-level drivers of the network evolution, we can predict the shape of the macro-structures that are likely to emerge and propose effective strategies to harness them to improve farmers' understanding of beneficial agricultural practices. This section describes the application of the method to the present data.

The model includes effects that represent possible reasons why an actor might wish to change a tie (Table 1). These effects express the actors' (not necessarily conscious) preferences for optimizing their communication network. They are related to the ego network structure, attributes of the ego, alters, and dyads. The goal of the simulation was to estimate the relative strength of these effects and their statistical significance.

In addition to the standard convergence tests described in the Appendix, we applied the following two approaches to guide the model selection and test the goodness of fit: (1) a generalized Neyman-Rao score-type test for each covariate; and (2) a test of the fit of the simulated networks in terms of the fundamental network characteristics that are not directly estimated in the simulations (Ripley et al., 2012).

Parameters for models that include more than one time period might not be constant over all periods. We used the score-type test to verify whether timeperiod dummy interactions with any parameter should be included or whether the parameters could be considered constant over all time periods. For example, in the presented models, it was necessary to add a time dummy for the distance covariate because the sensitivity of the farmers' phone calls to distance differed from the beginning to the end of the experiment.

For every new specification, we tested the model's goodness of fit by examining the simulated networks' fundamental characteristics that are not directly estimated by the methods of moments. We focused on the following four important properties of graphs (Wasserman \& Faust, 1994): (1) indegree distribution, (2) outdegree distribution, (3) geodesic distance distribution, and (4) triad census. Similar to Wang et al. (2009), we measured the Mahalanobis distance (Mahalanobis, 1936) to quantify how far the simulated networks are from the actual observations and employed a Monte Carlo test based on this distance to compute frequentist $p$-values for each of the four fundamental graph parameters (Lospinoso \& Snijders, 2011). The entire process was repeated until a well-converged model with high $p$-values for the Mahalanobis distance-based tests was obtained and all necessary controls for time heterogeneity were included.

We were not able to obtain a perfectly fitting model for all four tested graph properties when we used all six waves of data in the estimation, presumably partly because of initial irregularities and abrupt changes. The calling style observed in the first months, although illuminating for exploratory purposes, was atypical. Accounting for such time heterogeneity requires controlling for the changing strength of network effects through these initial phases of mobile network evolution. Such controls for all five periods between the six observed waves for each type of network resulted in overly complicated models, which either did not fit or did not converge. Therefore, we focused on longer-term regularities observable through initial and latter months of new phone experiences. Although the descriptive insights in this paper are based on the complete dataset, the network is simulated using twomonth rather than one-month periods in the presented Siena models. Specifically, we simulate the networks between the second, fourth, and sixth observations. This 
Table 1. Formulas and explanations for network selection and behavior effects in networks $x$ and $w$ for ego $i$, and alters $j$ with actor attributes $v$.

\begin{tabular}{|c|c|c|}
\hline Effect & Explanation & Formula \\
\hline Network effects & & $s_{k i}(x)$ \\
\hline Outdegree & $\begin{array}{l}\text { A tendency to create and } \\
\text { maintain calling ties }\end{array}$ & $\sum_{j} x_{i j}$ \\
\hline Reciprocity & $\begin{array}{l}\text { A tendency to call those } \\
\text { who call the ego }\end{array}$ & $\sum_{j} x_{i j} x_{j i}$ \\
\hline Three-cycles & $\begin{array}{l}\text { A tendency for generalized } \\
\text { reciprocity, i.e., to call } \\
\text { those who call those who } \\
\text { call the ego }\end{array}$ & $\sum_{j, h} x_{i j} x_{j h} x_{h i}$ \\
\hline $\begin{array}{l}\text { Indegree-related } \\
\text { popularity" }\end{array}$ & $\begin{array}{l}\text { A tendency to call those } \\
\text { who are called by others }\end{array}$ & $\begin{array}{l}\sum_{j} x_{i j} \sqrt{ } x_{+j}, \text { where } \sqrt{ } x_{+j} \text { is the } \\
\text { number of incoming ties of alter } \\
j\end{array}$ \\
\hline $\begin{array}{l}\text { Isolates' } \\
\text { withdrawal }\end{array}$ & $\begin{array}{l}\text { A tendency of those who } \\
\text { are not called by anyone } \\
\text { not to call anyone }\end{array}$ & $I\left\{x_{+i}=x_{i+}=0\right\}$ \\
\hline \multicolumn{3}{|l|}{ Actor effects } \\
\hline Ego attribute & $\begin{array}{l}\text { A tendency of actors with } \\
\text { certain attributes to create } \\
\text { and maintain calling ties }\end{array}$ & $\sum_{j} x_{i j} v_{i}$ \\
\hline Alter attribute & $\begin{array}{l}\text { Popularity of actors with } \\
\text { certain attributes as } \\
\text { targets of calls }\end{array}$ & $\sum_{j} x_{i j} v_{j}$ \\
\hline \multicolumn{3}{|l|}{ Dyadic effects } \\
\hline $\begin{array}{l}\text { Matching on } \\
\text { attributes }\end{array}$ & $\begin{array}{l}\text { A tendency to call those } \\
\text { with the same attributes }\end{array}$ & $\sum_{j} x_{i j} I\left\{v_{i=} v_{j}\right\}\left\{\begin{array}{c}I\left\{v_{i=} v_{j}\right\}=1, v_{i=} v_{j} \\
0, v_{i \neq} v_{j}\end{array}\right.$ \\
\hline Distance effect & $\begin{array}{l}\text { A tendency to call those } \\
\text { who live close }\end{array}$ & $\sum_{j} x_{i j} \log \left(\right.$ dist $\left._{i j}\right)$ \\
\hline \multicolumn{3}{|l|}{$\begin{array}{l}\text { Cross-network } \\
\text { effects }\end{array}$} \\
\hline Entrainment & $\begin{array}{l}\text { A tendency to call the same } \\
\text { people for expressive and } \\
\text { instrumental purposes }\end{array}$ & $\sum_{j} x_{i j} w_{i j}$ \\
\hline Behavioral effects & & $s_{k i}^{\text {beh }}(x, z)$ \\
\hline Linear change & $\begin{array}{l}\text { A basic drive toward } \\
\text { increasing calling volumes }\end{array}$ & $z_{i}$ \\
\hline Alters average & $\begin{array}{l}\text { A tendency of those who } \\
\text { call heavy callers to also } \\
\text { become heavy callers }\end{array}$ & $z_{i}\left(\sum_{j} x_{i j} z_{j}\right) /\left(\sum_{j} x_{i j}\right)$ \\
\hline
\end{tabular}

Note: $x_{i j}=1$ is a directed tie from $i$ to $j$ exists, 0 otherwise.

"The square root reflects that the same absolute difference in degree is relatively less relevant for high-degree individuals compared to low-degree individuals.

simplification considerably shortens the analysis time and enables us to obtain a good fit of the models.

During the model selection, we gradually tested the contribution of physical and social proximity as well as the ego, alter, and behavioral characteristics to the goodness of fit. In addition to the effects presented in the final models, we 

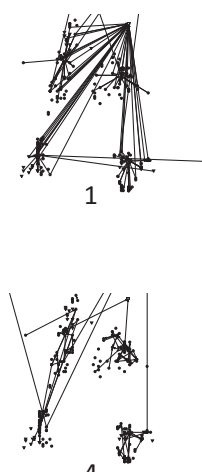

$\underline{4}$

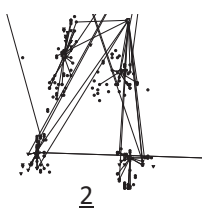

$\underline{2}$

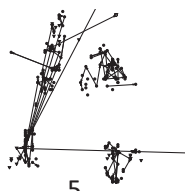

5
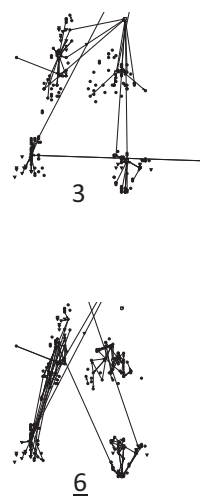

Fig. 1. A combined network of all types of calls for six monthly observations. The positions of the nodes correspond to their geographical locations.

experimented with constant and dynamic covariates of access to a phone signal and electricity, wealth, education, religion, and the ethnicity of the users. However, these covariates did not improve the fit of the models.

In the multivariate model, we used the same variables for both types of networks to obtain comparable results. We also tested various cross-network interactions such as the reciprocation of one type of calls with the other type or the effects of popularity in one network on popularity in other network. Surprisingly, these effects did not improve the fit of the model and were not statistically significant, which suggests a distinct nature of the type of communication and the resulting networks. The only cross-network effect that was significant was the most essential effect known as entrainment (Robins \& Pattison, 2006). A positive entrainment effect indicates that the presence of one type of tie between two actors in the previous wave increases the propensity for creation of the other type of tie between the same actors in the same direction.

\section{Results}

\subsection{Overall communication network}

First, we present descriptive findings about the overall communication network and call volumes (Figure 1, Table 2).

Table 2 demonstrates that at first, the new phone owners called distant individuals whom they met only through the experiment (and whose phone numbers they received from the distributed list). Many of these individuals were the agronomy specialists and the experiment organizers based in the centers of the villages, a nearby town, or near the capital in one case. (The town where several experts were based is located in the upper-right corner in the network figures.) The farmers mainly asked about new fertilizers and pests that appeared on their fields. Semi-structured interviews with the local experts showed that some experts attempted to answer the farmers' questions. However, several of the experts considered it a burden or believed that they could not give appropriate advice without visiting the farm and told the farmers not to call them again. Some experts also felt that in the beginning, many farmers called them simply to test their new phones. This type of usage sharply 
Table 2. Overall communication network and volume of calls.

\begin{tabular}{|c|c|c|c|c|c|c|}
\hline Observation time & 1 & $\underline{2}$ & 3 & $\underline{4}$ & 5 & $\underline{6}$ \\
\hline \multicolumn{7}{|l|}{ Overall communication network } \\
\hline Number of ties & 161 & $\underline{98}$ & 102 & 126 & 143 & 177 \\
\hline Average degree & 0.615 & $\underline{0 .} 375$ & 0.389 & $\underline{0} .483$ & 0.55 & $\underline{0} .694$ \\
\hline Reciprocated ties & 0 & $\underline{0}$ & 8 & $\underline{2} 2$ & 24 & $\underline{5} 0$ \\
\hline Missing & $2 \%$ & $\underline{2} \%$ & $2 \%$ & $\underline{\underline{2}} \%$ & $2 \%$ & $\underline{4} \%$ \\
\hline Median tie length $[\mathrm{km}]$ & 2.816 & $\underline{2} .423$ & 1.693 & $\underline{1} .394$ & 0.966 & $\underline{1} .314$ \\
\hline Ties with kin & $0 \%$ & $\underline{3} \%$ & $14 \%$ & $\underline{2} 3 \%$ & $30 \%$ & $\underline{2} 5 \%$ \\
\hline $\begin{array}{l}\text { Ties with alters who were met } \\
\text { through the experiment }\end{array}$ & $81 \%$ & $\underline{8} 0 \%$ & $62 \%$ & $\underline{4} 1 \%$ & $15 \%$ & $\underline{2} 0 \%$ \\
\hline \multicolumn{7}{|l|}{$\begin{array}{l}\text { Agricultural instrumental } \\
\text { communication network }\end{array}$} \\
\hline Number of ties & 146 & $\underline{87}$ & 84 & $\underline{7} 7$ & 52 & $\underline{4} 4$ \\
\hline Average degree & 0.56 & $\underline{0} .33$ & 0.32 & $\underline{0} .30$ & 0.20 & $\underline{0} .17$ \\
\hline Reciprocated ties & 0 & $\underline{\overline{0}}$ & 0 & $\underline{\overline{8}}$ & 0 & $\underline{\overline{0}}$ \\
\hline Missing & $2 \%$ & $\underline{2} \%$ & $2 \%$ & $\underline{2} \%$ & $2 \%$ & $\underline{4} \%$ \\
\hline Median tie length $[\mathrm{km}]$ & 2.797 & $\underline{2} .639$ & 1.754 & $\underline{1} .596$ & 1.372 & $\underline{2} .389$ \\
\hline Ties with kin & $0 \%$ & $\underline{2} \%$ & $9 \%$ & $\underline{1} 1 \%$ & $9 \%$ & $\underline{\overline{0}} \%$ \\
\hline $\begin{array}{l}\text { Ties with alters who were met } \\
\text { through the experiment }\end{array}$ & $87 \%$ & $\underline{8} 7 \%$ & $73 \%$ & $\underline{5} 6 \%$ & $41 \%$ & $\underline{7} 7 \%$ \\
\hline \multicolumn{7}{|l|}{ Expressive communication network } \\
\hline Number of ties & 4 & $\underline{3}$ & 11 & $\underline{29}$ & 49 & $\underline{3} 3$ \\
\hline Average degree & 0.02 & $\underline{0} .01$ & 0.04 & $\underline{0} .11$ & 0.19 & $\underline{0} .13$ \\
\hline Reciprocated ties & 0 & $\underline{\overline{0}}$ & 0 & $\underline{4}$ & 0 & $\underline{\overline{0}}$ \\
\hline Missing & $2 \%$ & $\underline{2} \%$ & $2 \%$ & $\overline{2} \%$ & $2 \%$ & $\overline{4} \%$ \\
\hline Median tie length $[\mathrm{km}]$ & 3.085 & $\underline{0} .938$ & 0.938 & $\underline{0} .922$ & 0.764 & $\underline{0} .889$ \\
\hline Ties with kin & $0 \%$ & $\underline{3} 3 \%$ & $42 \%$ & $\underline{5} 5 \%$ & $44 \%$ & $\underline{4} 8 \%$ \\
\hline $\begin{array}{l}\text { Ties with alters who were met } \\
\text { through the experiment }\end{array}$ & $25 \%$ & $\underline{3} 3 \%$ & $0 \%$ & $\underline{1} 0 \%$ & $0 \%$ & $\underline{6} \%$ \\
\hline \multicolumn{7}{|l|}{ Volume of calls } \\
\hline $\begin{array}{l}\text { Buying extra calling charge in the } \\
\text { given month (heavy calling }=1 \text { ) }\end{array}$ & 184 & $\underline{180}$ & 159 & 137 & 138 & $\underline{127}$ \\
\hline $\begin{array}{l}\text { Using only the freely provided } \\
\text { calling time (heavy calling }=0 \text { ) }\end{array}$ & 78 & $\underline{8} 1$ & 103 & 124 & 122 & 128 \\
\hline Heavy calling mean & 0.30 & $\underline{0} .31$ & 0.39 & $\underline{0} .48$ & 0.47 & $\underline{0} .50$ \\
\hline Missing & $2 \%$ & $\underline{2} \%$ & $2 \%$ & $\underline{2} \%$ & $2 \%$ & $\underline{4} \%$ \\
\hline
\end{tabular}

Note: Observations that are used in the presented stochastic models are underlined.

dropped after the initial period. The farmers gradually began to use their phones to call people who live closer and to speak with relatives. This shift from new weak ties to stronger and geographically shorter ties is documented in Table 2.

The stochastic actor-based modeling results show that the drivers of the overall communication network dynamics are reciprocity, indegree-related popularity, isolates' withdrawal, village boundaries, and geographical proximity (Table 4). Even within the same village, people are more likely to frequently call those who live closer. The negatively significant three-cycle time dummy suggests that the initial tendency toward generalized reciprocity disappeared toward the end of the experiment. After accounting for the effects of geography, transitivity effects (which test the actors' 
propensity to form closed triangles and increase the network clustering) did not further improve the fit of the model.

The outdegree effect is strongly negative, meaning that the users are reluctant to create and maintain calling ties unless several of the positive above-mentioned effects are also present (e.g., the calling partner lives physically close in the same village and has previously nominated ego). Consequently, the calling network is sparse (Table 2). In the semi-structured interviews, both farmers and local experts stated that they had never used their phones to call anyone whom they did not know. They would not feel comfortable doing that; moreover, it would be practically impossible to obtain phone numbers of people whom the individuals had never met in person. The strong isolates' withdrawal effect (parameter value: 2.848; standard error: 0.271) signifies that individuals who were not considered to be an important calling partner by any participant in the study were less likely to ever name a communication partner (not even their neighbors from the same village; parameter: 2.071; standard error: 0.287 ). Network normative mechanisms further aggravate the situation. Due to reciprocity effects, the passivity of the isolates lowers the probability of ever becoming a person's important calling partner in the future, which is further exacerbated by the indegreerelated popularity mechanism. Therefore, a large proportion of initially disconnected individuals remained isolated over the observed six months. In the last month of the experiment, $65 \%$ of the participants were not listed by another participant, and $56 \%$ did not list another participant.

The behavior-related variables are not significant. In addition to the formulas in Table 1, we attempted various other specifications but did not find any evidence of their effects in terms of influence or selection. It appears that people did not consider how often an alter calls in their choice of calling partners. Furthermore, their calling volumes were not significantly influenced by the calling volumes of their calling partners. However, the inclusion of these behavior variables affects the distributions of triadic motifs in the simulated networks and improves the overall fit of the univariate and multivariate models. Hence, they are preserved in the models.

\subsection{Instrumental and expressive communication networks}

This section aims to ascertain the potential of the mobile phone for development of (1) instrumental information-sharing and (2) expressive sentiment-sharing networks. The analysis highlights the importance of distinguishing conversation context when studying mobile phone calling networks. First, we focus on the instrumental agricultural information-sharing network, which was remarkably denser than the expressive communication network in the first months of the experiment (Table 2, and Figures 2 and 3). The initial period was presumably most influenced by the experiment design. The distribution of phones was administered with the assistance of local agricultural experts (who are the most educated people in the villages and have reliable information about the inhabitants), their phone numbers were given to the farmers, and the research purpose of exploring the transfer of agricultural information was known to the participants. This design may partly explain the high number of agricultural calling ties from the start. The high proportion of instrumental calls to alters (mainly the agricultural experts) who were met only through this project is remarkable (Table 2). 

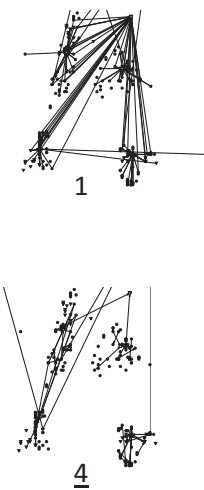

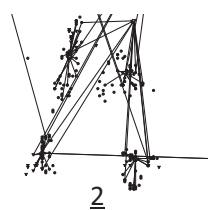

$\underline{2}$

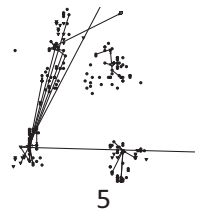

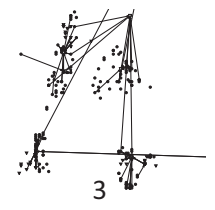

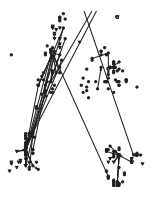

$\underline{6}$

Fig. 2. Instrumental communication network about agricultural information. The positions of the nodes correspond to their geographical locations.

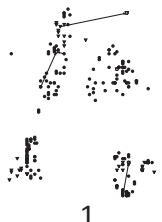

1

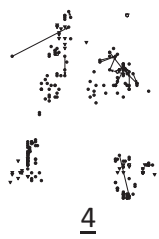

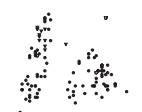

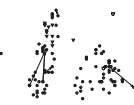

2
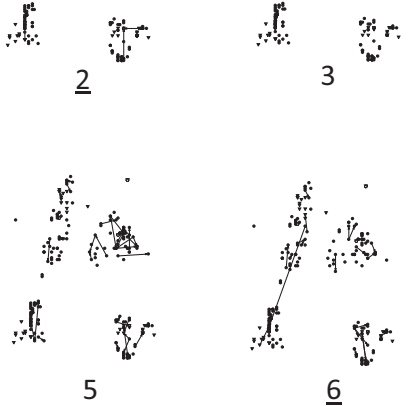

Fig. 3. Expressive communication network. The positions of the nodes correspond to their geographical locations.

A strong interconnection by instrumental calls can be noted between the two villages in the left-hand side of the network figures. The local informants explained that there are occasional interactions between these villages. The two villages are connected by a comfortable footpath without a large elevation difference and have a similar ethnic composition. Amhara is the largest ethnic group in the left-hand side villages, and the Oromo ethnicity is predominant in the right-hand side villages. Markets are held in the lower-left village, and some of the inhabitants of the upper-left village occasionally attend them. Finally, there is an agricultural office in the lower-left village that is used as a local coordination center, and the experts employed in this center disseminate the newest agricultural inputs.

In contrast, we did not find this inter-village connection for expressive calls. Figures 2 and 3, and Table 2 demonstrate that expressive communication partners tend to live closer than instrumental communication partners. Except for the extra ordinary start with only few expressive calls, the median tie length is slightly less than one kilometer. Interestingly, the median tie length of all types of measured social relationships among the inhabitants of this region prior to the experiment was 
Table 3. The number of ties that preserved their type and the number of ties that changed their type from expressive to instrumental or instrumental to expressive during each time period between observations.

\begin{tabular}{llllll}
\hline \hline Period & $1 \rightarrow 2$ & $2 \rightarrow 3$ & $3 \rightarrow 4$ & $4 \rightarrow 5$ & $5 \rightarrow 6$ \\
\hline Number of ties & & & & & \\
Instrumental $\rightarrow$ Instrumental & 48 & 28 & 25 & 18 & 16 \\
Instrumental $\rightarrow$ Expressive & 1 & 0 & 3 & 5 & 3 \\
Expressive $\rightarrow$ Expressive & 0 & 0 & 1 & 6 & 6 \\
Expressive $\rightarrow$ Instrumental & 0 & 1 & 0 & 0 & 2 \\
\hline \hline
\end{tabular}

approximately one kilometer (Matous et al., 2013). Table 2 shows a high proportion of kin among expressive phone communication partners.

Table 3 demonstrates that several ties changed their nature from instrumental to expressive and vice versa during the experiment. According to the stochastic multivariate models, these numbers signify actors' statistically significant preference for creating instrumental and expressive ties where the other type of relationship was previously present compared to calling a new alter. (The effect of a prior expressive tie on the creation of an instrumental tie $=4.398$, standard error: 2.095 ; the effect of a prior instrumental tie on the creation of an expressive tie $=3.674$, standard error: 0.988.) Table 3 shows that it is more common for expressive communication to follow instrumental communication than vice versa. However, in the actor-based model, due to the inclusion of the necessary controls for time heterogeneity that reflect the delayed onset in expressive communication, the entrainment effects are significant for both types of ties.

By comparing the parameter for the log of distance $(-0.767)$ and the entrainment parameter for expressive ties (3.674), we can illustrate the strength of the network interactions in geographical units. On average, calling a person for an expressive purpose in the first half of the experiment who lives only 100 meters away but had not provided instrumental information (i.e., entrainment $=0$ ) was as likely as calling a person who lives 12 kilometers away and had provided such information $\left(e^{3.674 / 0.767}=120 ; 100 \mathrm{~m} \times 120=12 \mathrm{~km}\right)$.

However, despite this interaction between the two communication networks, there are important differences in the mechanisms of their evolution. First, instrumentally important agricultural information-seeking calls are directed mainly to experts who have access to external information, whereas fellow farmers appear to be preferred for expressive calls. Next, differential impacts of physical distance are noteworthy. Compared to localized expressive communication, experiment participants obtained agricultural information with their phones across greater distances (Table 2). The actor-based model highlights that, controlling for a common village affiliation, the farmers preferred calling more distant individuals over their neighbors for information in the later in the experimental period (see the insignificant main effect of distance and the positively significant interaction with the time dummy in Table 4).

In the semi-structured interviews, several farmers described how they gradually realized that if they needed to request something from distant acquaintances, it was more productive to make a call and spend the saved time to work on the farm than to walk to meet them face-to-face. On average, the overall calling volumes rose 
Table 4. Network evolution parameters estimated using stochastic actor-based models.

\begin{tabular}{|c|c|c|c|c|c|c|}
\hline & \multicolumn{2}{|c|}{$\begin{array}{l}\text { Univariate model } \\
\text { All ties }\end{array}$} & \multicolumn{2}{|c|}{$\begin{array}{l}\text { Multivariate model } \\
\text { Agricultural } \\
\text { instrumental }\end{array}$} & \multicolumn{2}{|l|}{ Expressive } \\
\hline & Parameter & $\begin{array}{l}\text { Standard } \\
\text { error }\end{array}$ & Parameter & $\begin{array}{l}\text { Standard } \\
\text { error }\end{array}$ & Parameter & $\begin{array}{l}\text { Standard } \\
\text { error }\end{array}$ \\
\hline \multicolumn{7}{|l|}{ Network dynamics } \\
\hline \multicolumn{7}{|l|}{ Within-network } \\
\hline Outdegree & -6.435 & $(0.380)^{* * *}$ & -7.640 & $(1.698)^{* * *}$ & -10.246 & $(2.163)^{* * *}$ \\
\hline Reciprocity & 2.414 & $(0.252)^{* * *}$ & 2.652 & $(1.014)^{* * * *}$ & 0.318 & $(1.213)$ \\
\hline Cyclical triads & 1.628 & $(0.451)^{* * * *}$ & 2.209 & $(1.569)$ & 1.828 & $(1.351)$ \\
\hline $\begin{array}{l}\text { Indegree-related } \\
\text { popularity }\end{array}$ & 0.731 & $(0.133)^{* * * *}$ & 0.756 & $(0.299)^{* * *}$ & 1.195 & $(1.076)$ \\
\hline Isolates' withdrawal & 2.848 & $(0.271)^{* * *}$ & 3.794 & $(0.503)^{* * *}$ & 2.400 & $(0.844)^{* * *}$ \\
\hline $\begin{array}{l}\text { Physical distance } \\
(\log )\end{array}$ & -0.463 & $(0.056)^{* * * *}$ & 0.119 & $(0.153)$ & -0.767 & $(0.105)^{* * *}$ \\
\hline Alter is a farmer & -0.829 & $(0.219)^{* * *}$ & -2.626 & $(1.000)^{* * *}$ & 1.974 & $(1.011)^{*}$ \\
\hline Same village & 2.071 & $(0.287)^{* * * *}$ & 2.410 & $(0.491)^{* * *}$ & 3.038 & $(1.602)^{*}$ \\
\hline \multicolumn{7}{|l|}{$\begin{array}{l}\text { Controls for time } \\
\text { heterogeneity }\end{array}$} \\
\hline $\begin{array}{l}\text { Outdegree } \times \text { latter } \\
\text { time period }\end{array}$ & 0.261 & $(0.240)$ & 0.310 & $(0.322)$ & -0.147 & $(0.592)$ \\
\hline $\begin{array}{r}\text { Physical distance } \times \\
\text { latter time period }\end{array}$ & 0.017 & $(0.115)$ & 0.668 & $(0.185)^{* * *}$ & -0.033 & $(0.190)$ \\
\hline $\begin{array}{l}\text { Cyclical triads } \times \\
\text { latter time period }\end{array}$ & -2.672 & $(0.928)^{* * * *}$ & - & & & - \\
\hline \multicolumn{7}{|l|}{$\begin{array}{l}\text { Network } \\
\text { interdependence }\end{array}$} \\
\hline Entrainment & - & & 4.398 & $(2.095)^{* *}$ & 3.674 & $(0.988)^{* * *}$ \\
\hline \multicolumn{7}{|l|}{$\begin{array}{l}\text { Influence of calling } \\
\text { volumes on } \\
\text { network structure }\end{array}$} \\
\hline Alter calls heavily & -0.127 & $(0.231)$ & 0.178 & $(1.871)$ & 0.367 & $(0.783)$ \\
\hline Ego calls heavily & 0.187 & $(0.243)$ & -0.647 & $(1.588)$ & 0.196 & $(1.236)$ \\
\hline $\begin{array}{l}\text { Matching on calling } \\
\text { volumes }\end{array}$ & 0.420 & $(0.277)$ & 1.377 & $(1.752)$ & 0.516 & $(1.352)$ \\
\hline \multicolumn{7}{|l|}{ Behavior dynamics } \\
\hline $\begin{array}{l}\text { Control for a linear } \\
\text { change }\end{array}$ & 0.444 & $(0.228)^{*}$ & & & 0.514 & $(0.353)$ \\
\hline \multicolumn{7}{|l|}{$\begin{array}{l}\text { Influence of } \\
\text { network on } \\
\text { calling volumes }\end{array}$} \\
\hline Alters' average & -2.050 & $(2.506)$ & -3.204 & $(5.852)$ & -1.764 & $(14.397)$ \\
\hline Goodness of fit & \multicolumn{6}{|c|}{ Monte Carlo Mahalanobis distance test $p$-value } \\
\hline $\begin{array}{l}\text { Indegree } \\
\text { distribution }\end{array}$ & 0.823 & & 0.912 & & & \\
\hline $\begin{array}{l}\text { Outdegree } \\
\text { distribution }\end{array}$ & 0.411 & & 0.262 & & & \\
\hline $\begin{array}{l}\text { Geodesic distance } \\
\text { distribution }\end{array}$ & 0.548 & & 0.572 & & & \\
\hline Triad census & 0.146 & & 0.365 & & & \\
\hline
\end{tabular}

${ }^{*} p<0.1,{ }^{* *} p<0.05,{ }^{* * *} p<0.01$, two-sided. Rate effects not displayed. 
steadily (Table 2), even in places without electricity. Some experiment participants explained how they progressively mastered the functions of the phone while taking advantage of the free monthly calls and how they eventually began to purchase additional calling credit.

Nevertheless, many farmers who did not receive calls from others in the sample did not ever begin using their new phones for calls within the observed communities. Those who were not considered to be an important calling partner by any other participant tended not to name any calling partner from the sample (parameter: 3.794, standard error: 0.503 for instrumental call; and parameter: 2.400 , standard error: 0.844 for expressive calls). By the end of the experiment, $82 \%$ of farmers did not have an important calling partner within the sample to share their sentiments, and $85 \%$ did not have a calling partner for agricultural information sharing.

Although we expected sentiment sharing to be mutual, we did not see any evidence of reciprocal preferences in the respondents' nominations of main expressive communication partners. In contrast, the significant reciprocity effect for instrumental communication indicates that in this sparse network, the farmers were statistically significantly more likely to nominate individuals who nominated them in the previous wave as an important partner for information gathering compared to those who did not (only farmer-to-farmer ties can be reciprocated). This finding should be interpreted with caution because it does not necessarily imply high numbers of mutual ties within the same month. In fact, an immediate reciprocation by the same type of call within the same wave is nearly absent (Table 2). Nevertheless, this tendency suggests that in the long term, information does not need to flow in one direction only.

Finally, people are more likely to name an individual as an important information source if others also consider this individual to be important. This preferential attachment tendency was not evident for expressive calls.

\section{Discussion and conclusions}

The first aim of this study was to ascertain the potential of newly available mobile phones in rural areas of developing countries for the creation of networks that would enable agricultural information diffusion. The results suggest that mobile phones can be used to facilitate agricultural information-dissemination to remote rural households, but reports of social network expansion through the spontaneous creation of new instrumental ties may have been overstated in the literature. The new phone users expressed reluctance to call completely unknown individuals, and they typically do not know many people outside their small communities. However, the majority of the agricultural information-gathering calling ties registered in the panel were directed to individuals who were newly introduced through the experiment and whose phone numbers were distributed to the people. This outcome suggests a potential for organized interventions with this new technology.

As mobile phones become ubiquitous even in the rural regions of developing countries, the distribution of phone numbers to key persons could potentially aid in connecting remote farmers. It is unfortunate that this potential was not fully sustained in this particular case. In the present experiment, many farmers first tried to use their new phones to contact agricultural advisors, but many of the higher 
status experts did not wish to interact with the farmers outside of their prescribed work duties in the field and eventually expressed this feeling to the callers. If answering the calls from farmers was made a part of the governmental experts' work duties, these specialists could learn about the farmers' real problems, provide more useful external information from agricultural research centers, and serve as a bridge to other communities to which they are assigned.

In the longer term, the identified endogenous farmers' calling tendencies could be conducive to the creation of efficient macro-structures for large-scale information exchange. Paying greater attention to popular individuals is a self-reinforcing phenomenon that supports the emergence of high-degree hubs as prominent advisors become increasingly more popular and less known farmers become neglected. Due to this preferential attachment (and dis-attachment) in combination with the apparent statistical tendency to pay attention to those who have paid attention to you, the hubs might enable information flows in either direction through the network. Most importantly, the information could travel to these hubs directly from farms beyond a comfortable walking distance. Previous research has identified that the median length of all types of inhabitants' social ties (i.e., ties to a random sample of alters that egos know by name) prior to the experiment was approximately one kilometer (Matous et al., 2013). The phones where preferably used to gather information through weak ties to alters living beyond this distance and thus could not be met regularly (Table 2). Easier and more rapid communication through these geographically long and mostly weak ties creates shortcuts in the existing network and increases the potential for the diffusion of agricultural information.

By creating conditions with a fixed number of nodes from the start, we could identify the potential drivers of skewed degree distributions in isolation from network growth effects. As new farmers in the region gradually obtain phones and their new ties are added to the network (and some old instrumental ties are abandoned by farmers who prefer expressive usage), the relative importance of larger older nodes should gradually grow. Rather than arbitrarily selecting "pilot farmers," identifying and targeting any new calling network hubs with interventions is recommended. The agricultural experts are not eager to converse with many farmers; however, as a minimum requirement, their communication with selected highly regarded individuals would be beneficial.

A centralized information network topology resulting from the Mathew effect with newly possible geographically long ties would be an efficient type of structure in terms of network diffusion processes and robustness toward random node failure. However, this approach also entails risks because it may give a small number of individuals control over information flows across the network (Albert et al., 2000). Moreover, under natural conditions, socio-economically better-positioned individuals are able to obtain new communication technologies earlier and are more likely to become these privileged central nodes. Thus, the potential of the new technology to exacerbate power differentials within the affected communities should also be considered (Rogers, 2003).

The second aim of this study was to ascertain the potential of the mobile phone for the development of networks that would enable sentiment sharing in remote rural areas. After an initial period of testing the new devices predominantly as an agricultural information-gathering tool, people began using the phones for other 
gratifying activities, such as informally conversing with friends and family. According to the fears of some researchers, new communication technologies may damage the social capital of communities by replacing casual neighborly interactions with virtual communication with physically distant individuals (Putnam, 2000). The observed situation in the four villages does not support this bleak view. While informationseeking calls were preferably directed towards the most geographically distant alters within the existing egos' networks, the expressive ties were significantly shorter. Even after controlling for endogenous evolution mechanisms and homophily, the results show that the participants preferred to share their feelings with physically proximate alters. The median geographic length of an expressive communication tie (Table 2) was approximately the same as the length of the pre-existing ties, which were maintained face-to-face (Matous et al., 2013). This predominance of neighbors among expressive calling partners does not support the argument about the lost sense of community because of new technologies (Putnam, 2000). As reviewed above, there is a strong negative relationship between the physical distance and the frequency of meetings in this traditionally pedestrian region. Frequently met individuals are, in general, the preferred partners for expressive actions (Lin, 2001), which seems to be valid for phone-mediated communication.

In contrast to instrumental information sharing, expressive communication networks were fragmented and homophilous. By effectively preventing the emergence of long expressive inter-neighborhood ties, the strong frictional effects of distance indirectly limits the maximum possible degree within the spatially embedded expressive network in this sparsely populated region and sustains its fractioned nature (Barthélemy, 2011). It is unlikely that inter-communal sentiment-sharing social stars will emerge, and the phone seems unlikely to facilitate any large-scale diffusion of personal feelings. Moreover, due to the localized and disconnected nature of the expressive network and the limited geographical range of ties to trusted confidants, we do not expect the new mobile phone calling networks to be suitable for networkbased interventions that aim to fundamentally change people's basic behaviors. It seems unlikely that the calling networks will significantly accelerate extensive changes in habits such as the adoption of hand washing or diffusion of sensitive information (for example, information related to safe sexual practices) over large areas. The emerging, typically heterophilous, longer calling ties to little-known alters in the instrumental network are less likely to facilitate sharing delicate information or to have the strength to change people's fundamental private behaviors (Rogers, 2003).

Although it was shown that instrumental and expressive communication networks evolve in distinctly different patterns, these networks are related. The implication for studies on information-communication technologies for development is that the formation of knowledge-sharing structures can be better modeled and understood by factoring in social usage. When the networks were analyzed separately, as is often the practice in research investigating multiple networks, the fit of the models was unsatisfactory. However, if the overall network were analyzed without distinguishing the different purposes of calls, we would miss important divergent effects of geography and normative processes in instrumental and expressive communication network formation.

Finally, the validity of the shift in the number of ties from instrumental to expressive deserves discussion. Although we donated the phones unconditionally 
and the users were assured that they were free to use them for any purpose, it could be argued that the farmers might describe the content of their calls in ways that they expected would be considered desirable, particularly at the beginning of the experiment. The experts confirmed that they were indeed called for information most frequently in the beginning by the people whom they met during the experiment administration. This finding matches the data from the farmers. Secondly, the delayed appearance of kin among communication partners matches the delayed appearance of calls that were described as expressive (Table 2). As reviewed above, expressive actions are fundamental for human beings (Lin, 2001), and a possible explanation for the observed pattern is that as the novelty of the gadgets diminished, this fundamental human tendency to share sentiments was eventually reflected in the use of the new technology.

In conclusion, the current paper attempted to explain divergent evolutionary mechanisms of new information-sharing and casual calling networks after the introduction of mobile phones to an agrarian region that lacked informationcommunication technologies, mass media, and modern transportation infrastructure. Clearly, communication context is a critical variable to measure when studying phone communication networks. Methodologically, we hope that this study demonstrates the potential of combining an experimental design with longitudinal observations, qualitative interviews, and the latest advances in network statistical analytical techniques and goodness-of-fit tests to overcome some challenges facing current network research.

\section{Acknowledgements}

We thankfully acknowledge all advice and assistance from Tom Snijders, Christian Steglich, Johan Koskinen, Bernie Hogan, Joshua Lospinoso, Stanley Wasserman, Martin Everett, Mark Tranmer, Nick Crossley, Yasuyuki Sawada, Elisa Belotti, Denu Lemma, Ayako Ishiwata, Dagne Mojo, Tadesse Serefa, Yu Maemura, James McDaid, the participants of the Mitchel Centre For Social Network Analysis Seminar, the Nuffield Social Network Analysis Seminar, the Advanced Siena Users meeting in Arizona, the Tokyo Workshop on International Development, and four very helpful anonymous reviewers. The donation of the phones was financially supported by The Nakajima Foundation for Peace and the Ministry of Education, Culture, Sports, Science and Technology in Japan.

\section{References}

Agneessens, F., \& Wittek, R. (2012). Where do intra-organizational advice relations come from? The role of informal status and social capital in social exchange. Social Networks, 34(3), 333-345.

Akoglu, L., \& Dalvi, B. (2010). Structure, Tie Persistence and Event Detection in Large Phone and SMS Networks. Paper presented at the Proceedings of the Eighth Workshop on Mining and Learning with Graphs, Washington, D.C.

Albert, R., Jeong, H., \& Barabási, A.-L. (2000). Error and attack tolerance of complex networks. Nature, 406(6794), 378-382.

Arunachalam, S. (2002). Reaching the Unreached: How can we use ICTs to Empower the Rural Poor in the Developing World Through Enhanced Access to Relevant Information? Paper presented at the 68th IFLA Council and General Conference, Glasgow, Scotland.

Barabási, A.-L. (2009). Scale-free fetworks: A decade and beyond. Science, 325(5939), 412-413. 
Barabási, A.-L., \& Albert, R. (1999). Emergence of scaling in random networks. Science, 286(5439), 509-512.

Barthélemy, M. (2011). Spatial networks. Physics Reports, 499(1-3), 1-101.

Bewket, W. (2007). Soil and water conservation intervention with conventional technologies in northwestern highlands of Ethiopia: Acceptance and adoption by farmers. Land Use Policy, 24(2), 404-416.

Bhavnani, A., Chiu, R. W., Janakiram, S., \& Silarszky, P. (2008). The role of mobile phone in sustainable rural poverty reduction. Washington DC, USA: Policy Division (IBRD Telecommunications \& Information), World Bank.

Bodin, Ö., \& Crona, B. I. (2009). The role of social networks in natural resource governance: What relational patterns make a difference? Global Environmental Change, 19(3), 366-374.

Boissevain, J. (1974). Friends of friends: Networks, manipulators and coalitions. London: Basil Blackwell.

Boorman, S. A., \& Harrison, C. W. (1976). Social structure from multiple networks. II. Role structures. American Journal of Sociology, 81(6), 1384-1446.

Campbell, S. W., \& Kelley, M. J. (2008). Mobile phone use among alcoholics anonymous members: New sites for recovery. New Media \& Society, 10(6), 915-933.

Central Statistical Agency. (2004). The Federal Democratic Republic of Ethiopia Statistical Abstract for 2003. Addis Ababa, Ethiopia: CSA.

Deressa, T. T. (2007). Measuring the economic impact of the climate change on Ethiopian agriculture: Ricardian approach. Washington DC, USA: The World Bank.

Deressa, T. T., Hassan, R. M., Ringler, C., Alemu, T., \& Yesuf, M. (2009). Determinants of farmers' choice of adaptation methods to climate change in the Nile basin of Ethiopia. Global Environmental Change, 19(2), 248-255.

Donner, J. (2006). The use of mobile phones by microentrepreneurs in Kigali, Rwanda: Changes to social and business networks. Information Technologies and International Development, 3(2), 3-19.

Donner, J. (2008). Research approaches to mobile use in the developing world: A review of the literature. The Information Society, 24(3), 140-159.

Donner, J. (2009). Blurring livelihoods and lives: The social uses of mobile phones and socioeconomic development. Innovations: Technology, Governance, Globalization, 4(1), 91101.

Douthwaite, B., Keatinge, J. D. H., \& Park, J. R. (2001). Why promising technologies fail: the neglected role of user innovation during adoption. Research Policy, 30(5), 819-836.

Ellwardt, L., Steglich, C., \& Wittek, R. (2012). The co-evolution of gossip and friendship in workplace social networks. Social Networks, 34(4), 623-633.

Entwisle, B., Faust, K., Rindfuss, Ronald R., \& Kaneda, T. (2007). Networks and contexts: Variation in the structure of social ties. American Journal of Sociology, 112(5), 1495-1533.

Ferriani, S., Fonti, F., \& Corrado, R. (2013). The social and economic bases of network multiplexity: Exploring the emergence of multiplex ties. Strategic Organization, 11(1), 7-34.

Fischer, C. S. (1992). America calling: A social history of the telephone to 1940. Berkeley, USA: University of California Press.

Folke, C., (2006). Resilience: The emergence of a perspective for social-ecological systems analyses. Global Environmental Change, 16(3), 253-267.

Gao, J., Buldyrev, S. V., Stanley, H. E., \& Havlin, S. (2012). Networks formed from interdependent networks. Nature Physics, 8(1), 40-48.

Gebremedhin, B., \& Swinton, S. M. (2003). Investment in soil conservation in northern Ethiopia: The role of land tenure security and public programs. Agricultural Economics, 29(1), 69-84.

Granovetter, M. (1973). The strength of weak ties. American Journal of Sociology, 78(6), $1360-1380$. 
Harrison, C. W., Boorman, S. A., \& Breiger, R. L. (1976). Social structure from multiple networks. I. Blockmodels of roles and positions. American Journal of Sociology, 81(4), 730-780.

Hidalgo, C. A., \& Rodriguez-Sickert, C. (2008). The dynamics of a mobile phone network. Physica A: Statistical Mechanics and its Applications, 387(12), 3017-3024.

Homans, G. C. (1950). The human group. New York: Harcourt, Brace \& Company.

Horst, H., \& Miller, D. (2005). From kinship to link-up: Cell phones and social networking in Jamaica. Current Anthropology, 46(5), 755-778.

Huitsing, G., van Duijn, M. A. J., Snijders, T. A. B., Wang, P., Sainio, M., Salmivalli, C., \& Veenstra, R. (2012). Univariate and multivariate models of positive and negative networks: Liking, disliking, and bully-victim relationships. Social Networks, 34(4), 645-657.

Ilahiane, H., \& Sherry, J. W. (2012). The problematics of the "Bottom of the Pyramid" approach to international develpment: The case of micro-entreprenours' use of mobile phones in Morocco. Information Technologies and International Development, 8(1), 13-26.

International Telecommunication Union. (2009). Information Society Statistical Profiles 2009: Africa. Geneva, Switzerland: International Telecommunication Union.

Janssen, M. A., Bodin, Ö., Anderies, J. M., Elmqvist, T., Ernstson, H., Mcallister, R. R. J., Olsson, P., \& Ryan, P. (2006). Toward a network perspective of the study of resilience in social-ecological systems. Ecology and Society, 11(1), 15.

Juma, C. (2010). The new harvest: Agricultural innovation in Africa. New York, USA: Oxford University Press.

Kadushin, C. (2012). Understanding social networks: Theories, concepts, and findings. Oxford, UK: Oxford University Press.

Krackhardt, D., \& Stern, R. N. (1988). Informal networks and organizational crises: An experimental simulation. Social Psychology Quarterly, 51(2), 123-140.

Krings, G., Calabrese, F., Ratti, C., \& Blondel, V. D. (2009). Urban gravity: A model for inter-city telecommunication flows. Journal of Statistical Mechanics: Theory and Experiment, 2009(7), 1-8.

Lambiotte, R., Blondel, V. D., de Kerchove, C., Huens, E., Prieur, C., Smoreda, Z., \& Van Dooren, P. (2008). Geographical dispersal of mobile communication networks. Physica A: Statistical Mechanics and its Applications, 387(21), 5317-5325.

Lazega, E., Mounier, L., Snijders, T., \& Tubaro, P. (2012). Norms, status and the dynamics of advice networks: A case study. Social Networks, 34(3), 323-332.

Leeuwis, C. (2004). Communication for rural innovation: Rethinking agricultural extension. Ede, the Netherlands: Blackwell Publishing Ltd.

Leicht, E. A., \& D'Souza, R. M. (2009). Percolation on interacting networks. arXiv:0907.0894.

Lin, N. (2001). Social capital: A theory of social structure and action. Cambridge, UK: Cambridge University Press.

Lospinoso, J. A., \& Snijders, T. A. B. (2011). Goodness of Fit for Social Network Dynamics. Paper presented at the Sunbelt XXXI, St. Pete's beach, Florida, USA.

Mahalanobis, P. C. (1936). On the generalised distance in statistics. Proceedings of the National Institute of Sciences of India, 2(1), 49-55.

Matous, P., \& Todo, Y. (2013). Mobile Phones and Compost in Ethiopia: Reshaping Ecological Learning Networks by Text-Messaging. Paper presented at the XXXIII Sunbelt Social Networks Conference of the International Network for Social Network Analysis, Hamburg, Germany.

Matouš, P., Todo, Y., \& Mojo, D. (2012). Roles of extension and ethno-religious networks in acceptance of resource-conserving agriculture among Ethiopian farmers. International Journal of Agricultural Sustainability, 11(4), 301-316. 
Matous, P., Todo, Y., \& Mojo, D. (2013). Boots are made for walking: interactions across physical and social space in infrastructure-poor regions. Journal of Transport Geography, 31, 226-235.

Matous, P., Tsuchiya, T., \& Ozawa, K. (2011). Farmers' access to resources via networks in remote rural areas with mobile phone reception: Creating a resource battery for a mountain tribe in south India. Rural Society Journal, 20(2), 174-186.

May, J. D. (2012). Digital and other poverties: Exploring the connection in four east African countries. Information Technologies \& International Development, 8(20), 33-50.

McPherson, M., Smith-Lovin, L., \& Cook, J. M. (2001). Birds of a feather: Homophily in social networks. Annual Review of Sociology, 27, 415-444.

Mojo, D., Todo, Y., \& Matous, P. (2010). Perception of farmers and agricultural professionals on changes In productivity and water resources in Ethiopia. World Academy of Science, Engineering and Technology, 1(66), 860-868.

Mok, D., \& Wellman, B. (2007). Did distance matter before the Internet? Interpersonal contact and support in the 1970s. Social Networks, 29(3), 430-461.

Molm, L. D., Schaefer, D. R., \& Collett, J. L. (2007). The value of reciprocity. Social Psychology Quarterly, 70(2), 199-217.

Mucha, P. J., Richardson, T., Macon, K., Porter, M. A., \& Onnela, J.-P. (2010). Community structure in time-dependent, multiscale, and multiplex networks. Science, 328(5980), 876878.

Onnela, J.-P., Saramäki, J., Hyvönen, J., Szabó, G., Lazer, D., Kaski, K., . . Barabási, A.-L. (2007). Structure and tie strengths in mobile communication networks. Proceedings of the National Academy of Sciences, 104(18), 7332-7336.

Ostrom, E., (1990). Governing the commons: the evolution of institutions for collective action. Cambridge: Cambridge University Press.

Overå, R. (2006). Networks, distance, and trust: Telecommunications development and changing trading practices in Ghana. World Development, 34(7), 1301-1315.

Peters, O., \& Allouch, S. B. (2005). Always connected: A longitudinal field study of mobile communication. Telematics and Informatics, 22(3), 239-256.

Pretty, J., Toulmin, C., \& Williams, S., (2011). Sustainable intensification in African agriculture. International Journal of Agricultural Sustainability, 9(1), 5-24.

Putnam, R. (2000). Bowling alone. New York, USA: Simon and Schuster.

Ripley, R., Snijders, T. A. B., \& Preciado, P. (2012). Manual for SIENA version 4. Oxford, UK: University of Oxford.

Robins, G., \& Pattison, P. (2006). Multiple Networks in Organizations. Retrieved on 25 June 2012 from http://www.sna.unimelb.edu.au/publications/multiple_networks.pdf.

Rodriguez, M. A., \& Shinavier, J. (2010). Exposing multi-relational networks to singlerelational network analysis algorithms. Journal of Informetrics, 4(1), 29-41.

Rogers, E. M. (2003). Diffusion of innovations (5th ed.). New York, USA: Free Press.

Schneider, F., Fry, P., Ledermann, T., \& Rist, S. (2009). Social learning processes in Swiss soil protection-The 'From Farmer - to Farmer' project. Human Ecology, 37(4), 475-489.

Singer, B. D. (1981). Social functions of the telephone. Palo Alto: R\&E Research Associates, Inc.

Snijders, T. A. B. (2001). The statistical evaluation of social network dynamics. Sociological Methodology, 31(1), 361-395.

Snijders, T. A. B., Lomi, A., \& Torló, V. J. (2013). A model for the multiplex dynamics of twomode and one-mode networks, with an application to employment preference, friendship, and advice. Social Networks, 35(2), 265-276.

Snijders, T. A. B., van de Bunt, G. G., \& Steglich, C. E. G. (2010). Introduction to stochastic actor-based models for network dynamics. Social Networks, 32(1), 44-60. 
Solano, C., Leon, H., Perez, E., \& Herrero, M. (2003). The role of personal information sources on the decision-making process of Costa Rican dairy farmers. Agricultural Systems, 76(1), 3-18.

Spielman, D. J., Ekboir, J., \& Davis, K. (2009). The art and science of innovation systems inquiry: Applications to Sub-Saharan African agriculture. Technology in Society, 31(4), 399-405.

Steglich, C., Snijders, T. A. B., \& Pearson, M. (2010). Dynamic networks and behavior: Separating selection from influence. Sociological Methodology, 40(1), 329-393.

Szell, M., Lambiotte, R., \& Thurner, S. (2010). Multirelational organization of large-scale social networks in an online world. Proceedings of the National Academy of Sciences, 107(31), 13636-13641.

Szell, M., \& Thurner, S. (2010). Measuring social dynamics in a massive multiplayer online game. Social Networks, 32(4), 313-329.

Wang, P., Sharpe, K., Robins, G. L., \& Pattison, P. E. (2009). Exponential random graph (p*) models for affiliation networks. Social Networks, 31(1), 12-25.

Warner, K. D. (2007). Agroecology in action. Cambridge, USA: The MIT Press.

Wasserman, S., \& Faust, K. (1994). Social network analysis: Methods and applications. Cambridge, UK: Cambridge University Press.

Wellman, B., \& Tindall, D. B. (1993). Reach out and touch some bodies: How social networks connect telephone networks. In G. Barnett \& W. Richards (Eds.), Progress in communication science, vol. 13 (pp. 63-93). Norwood, USA: Ablex.

\section{Appendix}

This appendix explains the method of stochastic actor-based simulation for multiplenetwork evolution. The simulation conditions on the first observation and tests hypothetical drivers of the evolution of networks and behaviors observed in the following periods. The model assumes a continuous Markov evolution of the network and decomposes the observed changes in its smallest possible components, i.e., modifications of one tie or one person's behavior at a time between observations.

Between the observations, each actor receives several opportunities in a random order to change one of her outgoing ties and, in models that include it, several opportunities to change her behavior. The model includes "rate effects" for each simulated network and for the behavior that regulates how often actors receive an opportunity to modify their outgoing ties in each network or their behavior. These rate effects depend on the number of observed changes within the period. Only one actor acts at a time, and coordination is not allowed.

Each actor's decision constitutes the social context in which she is embedded, and she chooses the next move to myopically maximize her utility. Utility is expressed, as in generalized linear models, as a combination of hypothetically relevant network features and behavior. In the simplest form, the utility can be expressed as $f_{i}(\beta, x)=$ $\sum_{k} \beta_{k} s_{k i}(x)$. The utility function quantifies the desirability of each possible next state of the network $x$ among the fixed set of actors from the viewpoint of actor $i$. A random component with a standard Gumbel distribution is added to the evaluation function. This procedure is included to respect the stochastic character of network evolution, which is a result of influences that are unrepresented by nodal or dyadic variables and of measurement errors. Thus, the actor does not necessarily choose the state with the highest utility, but such a choice is most likely. When an actor receives an opportunity to modify one of her networks, her options are to create one 
new tie, delete one existing tie, or do nothing. When an actor has an opportunity to change her behavior, in the case of a dichotomous behavioral variable, the actor can choose to toggle the behavioral state or remain the same. Separate utility functions are evaluated for actors' choices in each network and for a behavior.

Each effect $s_{k i}$ in the model corresponds to possible reasons why an actor might wish to change a tie or a behavior. These effects express the actors' (not necessarily conscious) preferences for optimizing their communication network. They may be related to the actors' ego network structure, attributes of the ego, alters, or dyads. The actors' covariates can be constant (such as ethnicity or geographical distance), exogenously changing (such as availability of electricity or phone signal), or endogenously changing (i.e., actors' behavior). The explanations and mathematical formulas of effects $s_{k i}$ are presented in Table 1. Please see the Siena manual (Ripley et al., 2012) for a more in-depth explanation and a graphical illustration of the effects.

The goal of the simulation is to estimate the relative weights $\beta_{k}$ for the statistics $s_{k i}$. Parameter estimates can be used to compare how attractive various tie or behavioral changes are to the actors while controlling for other exogenous and endogenous effects. The signs of $\beta_{k}$ indicate the preferred directions of network or behavioral change, and their relative magnitudes can be interpreted similarly to parameters of multinomial logistic regression models in terms of the log-probabilities of changes among which the actors can choose. For example, in the evaluation function of network $x_{1}$, if an effect indicating a presence of a tie in network $x_{2}$ between actor $i$ and actor $j$ is statistically significant and positive, then actor $i$ is more likely to create and maintain a tie in $x_{1}$ to alters with whom a tie in $x_{2}$ exists, ceteris paribus. Thus, both networks serve as both explanatory and outcome variables.

For models with more than two observations, all parameters are held the same for each period, except for the rate of change. In the simulation, the network is reset to the observation $x\left(t_{m}\right)$ whenever the observation parameter $t$ passes the time $t_{m}$.

The estimation was executed in SIENA package version 4 in $\mathrm{R}$ and employed its new functions for multiple network analysis (Ripley et al., 2012). The method of moments, which depends on thousands of iterative computer simulations of the change process (Snijders, 2001), is used to estimate the parameters $\beta_{k}$ that enable the reproduction of networks observed over six months most closely in terms of selected target statistics. There is one target statistic for each estimated effect (for example, the number of ties in the network corresponds to the outdegree effect, the number of reciprocated ties corresponds to the reciprocity effect, the number of feed forward loops corresponds to the transitivity effect, and the amount of change in network corresponds to the rate function). For simulations over multiple periods, the statistics are summed over all periods. The presented models all converged with $T$-ratios, quantifying the deviations between the simulated and the observed values of the target statistics, between -0.1 and 0.1 , which indicates an excellent model convergence (Ripley et al., 2012). In the final stage of the simulation, the standard errors of the estimated parameters are computed by the finite difference method, based on the sensitivity of the target statistics to $\beta_{k}$. The presented models respect the restraint that farmers could not name more than five calling partners and the fact that experts in the experiment did not call farmers, i.e., the maximum outdegree is set to five, and experts do not initiate ties in the simulations (outgoing ties are all fixed as structural zeroes). 